\title{
When Claims of Understanding Are Less Than Affiliative
}

\author{
Ann Weatherall and Leelo Keevallik
}

\author{
Journal Article
}

\section{Tweet}

N.B.: When citing this work, cite the original article.

This is an electronic version of an article published in:

Ann Weatherall and Leelo Keevallik, When Claims of Understanding Are Less Than Affiliative, Research on Language and Social Interaction, 2016. 49(3), pp.167-182.

Research on Language and Social Interaction is available online at informaworldTM:

http://dx.doi.org/10.1080/08351813.2016.1196544

Copyright: Taylor \& Francis (Routledge): SSH Titles

http://www.routledge.com/

Postprint available at: Linköping University Electronic Press

http://urn.kb.se/resolve?urn=urn:nbn:se:liu:diva-132087

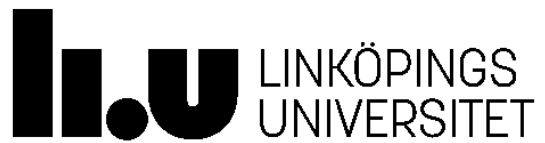


When claims of understanding are less than affiliative

Ann Weatherall ${ }^{1}$ and Leelo Keevallik ${ }^{2}$

${ }^{1}$ Victoria University of Wellington, New Zealand

${ }^{2}$ Linköping University, Sweden

Word count (including non-English language extracts): 9434

*correspondence should be addressed to Ann Weatherall: Ann.Weatherall@vuw.ac.nz

Key words: alignment, conversation analysis, deontics, discursive psychology, interactional linguistics, intersubjectivity. 


\begin{abstract}
Conversation analysis has established that the smooth progression of interaction and the accomplishment of action rests on joint understanding, which is implicitly built by a next turn of talk. In this article we examine explicit claims to intersubjective understanding from a range of settings from the institutional to the mundane. Our target expressions have the general form; I + 'understand' + YOU + PSYCHOLOGICAL FORMULATION such as I understand your concern and I see that this is frustrating you. We propose these expressions do "pro forma" affiliation - that is, they make a show of affiliating, even if in fact there is no affiliation. By explicitly claiming and demonstrating an understanding of the other speaker's subjectivity, our target expression orients to misalignment between the parties, makes a show of other-attentiveness and bridges a shift that advances a speaker's interactional agenda. Our contribution is to show the strategic function of a previously undocumented pro-social grammatical-conversational structure. Data are in English, and in Estonian and Swedish with English translation.
\end{abstract}


Sacks (1992) made a distinction between demonstrating and claiming understanding. For example, a recipient can demonstrate understanding of a place reference by using an alternative formulation of the same location. In contrast, a receipt token such as 'yip' would merely claim understanding. Common understanding underpins the smooth progression of interaction and the successful accomplishment of joint actions. A next turn of talk normatively and implicitly displays an understanding of the prior one, thus the sequential organisation of social interaction provides an infrastructure for intersubjectivity (Heritage, 1984; Schegloff, 2007; Mondada, 2011). To utter an explicit claim of understanding another person is therefore a marked social action that can be investigated for its meaning for the participants.

The present study examines explicit claims of understanding something about another person's psychological state. Our target expressions have the general but flexible format consisting of the first person reference followed by a verb that is either prototypically or metaphorically used for claiming understanding (i.e., I understand, I see) in combination with a formulation of the recipient's subjectivity involving reference to the second person (e.g. you, your) and what we gloss as a psychological formulation (e.g. concern, frustrated, craving). This second part of the expression is a demonstration of what has just been claimed as understood about the other's subjectivity. Instances include I see that this is frustrating you and I understand that you are craving for coffee. In short, our target is a semi-fixed expression that can be represented as I+ 'understand' + YOU + PSYCHOLOGICAL FORMULATION. We will be arguing that these explicit claims of understanding the other's mind do "pro forma" affiliation - that is affiliation in name only - because they seem attentive to the other by claiming and demonstrating understanding of their subjectivity, but actually are not.

Languages contain a rich variety of everyday psychological concepts that can be studied for what they do. The practical uses of terms from the "cognitive thesaurus" (Potter, 2006, p. 132) is one of the general concerns of discursive psychology. It is an approach that seeks to understand the rhetorical deployment of psychological words such as thinking, knowing and feeling. Taking 
cognitivism as a theoretical point of departure it treats psychological descriptions as deriving their intelligibility from their contexts of use and not from being referential to some mental state (Edwards, 1997). Discursive psychology shares with other approaches to language-in-use such as interactional linguistics and conversation analysis the view that what people say and do in ordinary talk is coherent and systematically organised to support positive sociality (Edwards, 1995). The organisation of dispreferred actions is one example of conversational structures supporting social solidarity (Heritage, 1988; Schegloff, 2007). Token agreement strategies (e.g. yes but) are another. They were first documented in English (Pomerantz, 1984) and have since been found in other languages including Finnish (Niemi, 2014) and German (Szczepek Reed, 2015). Our examination of the situated and strategic use of an expression that draws twice on the cognitive thesaurus lies clearly at the intersection of discursive psychology and interactional studies.

A range of psychological expressions, albeit less complex than the one we examine have been investigated for what they do in talk. Those in the first person include, I don't know (Keevallik, 2006; Weatherall, 2011), I guess (Kärkkäinen, 2007), I think (Kärkkäinen, 2003) and I thought (Smith, 2013). In our broader collection of claims to the intersubjective I understand recurrently occurred and became the focus of our analysis. It has been described as indicating, showing or claiming that some kind of mental effort has taken place (Coulter, 1979; Lindwall \& Lymer, 2010).

In contrast to research on I + cognitive-verb constructions studies of YOU + PSYCHOLOGICAL FORMULATIONS - the second part of our target expression - are relatively sparse, perhaps reflecting that it is a less frequent practice. A number of examinations have focused on you know as a pragmatic particle in different languages (Asmuss, 2011; Lindström \& Wide, 2005; Schiffrin, 1987). Turns prefaced with you mean have been analysed as offering candidate understandings. Antaki (2012) showed that they can be used disaffiliatively as well as affiliatively, which can result in different action trajectories. Related expressions such as so what you're saying is or so you mean mark were used in radio call-in programs by the host to challenge the caller's views (Drew, 2003). In clinical therapeutic encounters where shifting a client's way of thinking is a goal of the interaction, 
roundabout formulations of the other's perspective seem to be used, such as references to how things look to them (Muntigl \& Horvath 2014) or impersonal formats such as it feels (Drew, 2003). Formulating the other is of course an essential component of certain activities, such as therapy. One of the cases in our collection I can understand how you'd think that was from telephone counselling. However, we left it aside for the time being because we wanted to know how our expression functioned in contexts other than where it is constitutive of the business at hand.

Our target expression construes two separate psychological entities (i.e., me and you) by explicitly referencing them in talk. A claim of 'understanding' and the demonstration of what that means creates an impression of unity and consensus that seemingly bridges that separateness. It is a linguistic pattern that targets what Linell (2009) described as the ever-present tension between intersubjectivity and oneness across individuals on the one hand, and their differences and multiplicity of opinions on the other.

To the best of our knowledge, there are no systematic interactionally sensitive studies of explicit claims to the intersubjective of the form we collected. The goal of our investigation was to discover how this specific linguistic structure that claims and formulates something in the recipient's psychological realm is deployed and for precisely what purpose.

\section{Data and Method}

The data for this study were drawn from a large variety of naturally occurring recorded interactions from mundane, workplace and institutional settings. They included telephone calls and copresent interactions. The data were English (American, Australian and New Zealand varieties), Estonian and Swedish. All participants have agreed to the recordings being used for research purposes, and they have been anonymized in the presented excerpts. Nearly 100 instances of claims to intersubjectivity were collected - about half of which were in English and about 20 in Estonian with the remaining cases in Swedish.

We first cast our net broadly to extract all kinds of intersubjective claims. The 100 initial cases covered a broad range of psychological expressions including 'I think', 'I guess', 'I know' and 'I see'. We 
chose to focus on 20 instances of 'I understand' in either literal or metaphorical sense (6 in Estonian, 3 in Swedish, 11 in English) in the first half of the expression. That included, for example, some instances of ' see' and 'I know' in English. The second half of the expression was a specific claim about a recipient's subjectivity. We gloss these as psychological formulations because they included references to the other person's desires, emotions, intentions, meaning and motivations.

We subscribe to the view that meaning is locally accomplished between the current speakers. Linguistic resources, such as the verbs and nouns in our collection, have semantic potentials that contribute to generating situated meanings in combination with contextual resources (Linell 2009: 221236). We therefore simply included words that are regularly, or perhaps even prototypically, used to refer to psychological states and processes, without predetermining their semantics in specific instances. This is what the studies of the cognitive thesaurus in discursive psychology are about - how psychological terms and concepts are mobilised in talk to do things (Potter, 2006, p.32).

Likewise, there is no doubt that the various lexical items have somewhat diverging semantic potentials in our three languages. Nevertheless, there clearly is an overlap within our focus domain of referring to psychological states and processes, most crucially a claim to 'understanding' the recipient's subjectivity. The lexical inventories arrived at through the searches ended up being somewhat different, as did the precise grammatical formats.

We considered the number of cases large enough to discover regularities in the specific forms it took and the actions it accomplishes. However, the collection is relatively small to the sizeable amount of material examined suggesting it is a recognizable but reasonably infrequent practice.

A conversation analytic approach was used to discover generic features of the phenomenon across its idiosyncratic manifestation in particular instances (Schegloff, 1996). Each case was examined closely and in detail for its particular composition (semantically and syntactically) and position (within turn and sequence) and the ways it was implicated in observably relevant aspects of action.

\section{Analysis}


The analysis begins by presenting three cases of our target expression being used in one institutional setting. In these cases, the claim to understanding the other's subjectivity clearly occurs where a display of affiliation is relevant which we use as evidence supporting our proposal it does pro forma affiliation. The similarities across the first three cases in terms of format and sequential position render it almost formulaic. Having shown its use in one setting, we go on to provide further evidence that claims to the intersubjective are doing pro-forma affiliation in three other settings including mundane talk-in-interaction. The expressions in these cases are not in affiliation relevant positions. Rather they occur where there is clear misalignment in the particular activity each party is involved in. The pro forma affiliation in these later cases is not due to immediate sequential position. Instead it is some other threat to the positive sociality, such as criticism, that underpins its use.

\section{Claims to the Intersubjective in Affiliation-Relevant Positions}

The first three cases come from a New Zealand telephone dispute resolution service for customer complaints about electricity and gas. The analysis of the first example examines our target in particular detail in order to show how its various facets emerge. An important aspect of the institution is that it is an independent body - it is neither consumer advocacy nor for the benefit of the utility companies. Calltakers are expected to be neutral about caller's complaints. Weatherall (2015) found displays of affiliation - alignment with the caller's stance - were oriented to as a restricted activity. We will show that in this setting our target expressions occur when a display of affiliation is relevant and there is misalignment with respect to action.

The dispute resolution service mediates between customers and the utility providers on particular kinds of issues set out in law. For example, electricity companies are required to read a customer's meter four times a year, which is a matter at stake for two of the three cases presented below. The tasks of the service include establishing if there is a problem that falls within the institutional remit and ensuring the customer has already approached the company about it. A regular outcome of complaint calls is that the service instructs the company to contact the customer and make an offer that resolves their problem, for 
example establishing a payment plan. If the customer is not happy with the outcome then the dispute gets referred to the ombudsman who makes a binding ruling.

The complaint in Extract 1 is about an unaffordable power bill. The caller is blaming the electricity company for sending bills based on estimated rather than actual power usage. The calltaker has established the underestimations occurred because power usage has changed with the recent installation of a heat pump. The caller would like the electricity company to make meter readings every month.

We join the interaction just after the conciliator call-taker (CONC in the extract) has summarised what will happen next in the dispute resolution process - the service will tell the company to contact the customer to reach a resolution. The extract begins with agreement to that course of action yeah no that sounds fine (line 15). The caller then complains once again about not getting the previously requested monthly meter readings. Our target expression occurs in line $26-$ the conciliator call-taker makes an explicit claim to understanding the caller's psychological state - in this case formulated as a concern. The analysis examines in detail what each party is doing in this sequence.

Extract 1 Three-thousand dollar power bill (NZE)

15 CALL: yeah no that sounds fi:ne I m[ean ]I just I just wanna get it

16 CONC: [okay]

17 CALL: sorted and [see ] why again (. ) our power hasn't been read= 18 CONC: [yeah]

19 CALL: =for this month.

21 CONC: Right. .h [ o h k a y. ]

22 CALL: [I mean is it ]gonna be: $(\odot .2)$ another two months or another three months $o(h) r$ before we know it we're gonna have over a threethousand dollar powerbill come Christmas 25 time 
26->CONC: yeah I I understand your co- your concern about that

27

28

29

30

31

32

33

34 CALL: well it was- it was summertime anyway

35 CONC: yeah $(\odot .7)$

Um one- one thing you could do is (.) is $\mathrm{u}: \mathrm{m} . \mathrm{h} \mathrm{d}^{\prime}$ you

know hh hh I mean >I know< (.) obviously it's a little bit different cos if ${ }^{\circ}$ ifo any of $y$ - Your consumption's changed you may not know what ya .h general monthly .h account is= $=$ the general mon- monthly account: $(0.2)$ normally sits at (.) I'll just pull one out of the fi:le, .hh: $u:: m$

Our expression occurs in response to the caller complaining, for another time, about the frequency of meter readings (lines 15-25). The caller says she wants to see why the meter hasn't been read- that is, she is seeking an explanation, which is one indication of the 'complainability' of something (Bolden \& Robinson, 2011; Schegloff, 2005); negative formulations (i.e. power hasn't been read) are another (Schegloff, 2007). The problem is construed as a persistent one - again functioning rhetorically to work up its severity and to ward off an attribution that the caller is characteristically a whinger (Edwards, 2005).

A relevant response to a troubles-telling by a properly aligned troubles-recipient is a display of affiliation; typically some kind of stance endorsement. Jefferson (1988) suggested that in ordinary conversation affiliation is a preferred response to a troubles-telling and basic to its progression to closure. In the above case saying something like you really do need to get the meter read now would show affiliation with the trouble. Such a response in this institutional setting would side with the caller, which is a restricted activity (Weatherall, 2015). What the call-taker actually does is receipt the information with right, which registers the previous turn but displays no particular stance towards it. Right can be used to mark a progression of understanding and is regularly found at major activity shifts (Gardner, 2007). After right the call-taker makes an audible in-breath followed by okay, 
perhaps a sign of trouble and an indication of a readiness to move to a next activity (Beach, 1993). The call-taker's right okay response shows no affiliation with the caller's complaint.

This inadequate affiliation to a troubles-telling leads to its expansion, a typical continuation in this context (Couper-Kuhlen 2012). It is prefaced by I mean, which works to defend against a lack of recipient stance alignment by suggesting the complaint so far requires further explication (Maynard 2013). In the above extract, I mean is it gonna be another two months or another three months... (line22) expands on the trouble about the power not being read by narrating a disastrous future if it does not happen...or before we know it we are going to have a three thousand dollar power bill come Christmas time. As suggested by Maynard, the expansion in the above case provides another opportunity for the call-taker to affiliate by endorsing the caller's stance. The affiliationrelevant turn-taking slot contains our target expression I-I understand your co- concern.

The initial element of that turn is yeah - an acknowledgement but little else of what has just come prior, as it cannot be heard as a literal answer to the rhetorical yes/no question. A properly aligned call-taker would treat the complaint as a legitimate dispute to be resolved. I understand your concern is not an aligning response because it does not progress the complaint as a dispute for resolution. Furthermore, it is an expression that seems affiliative but falls short of that because it simply references the teller's stance, rather than ratifying it by supporting her affective stance.

The expression, I understand your concern not only claims understanding but demonstrates what that understanding is by construing it as a subjective matter-your concern. The call-taker is stating she, as a subject, sees or appreciates the caller's perspective (the verb captures both these shades of meaning). The speaker and the recipient are thus cast as separate entities in the world. Being at-one-with-the-other is the kind of intersubjectivity that underpins the joint accomplishment of action. The claim to the intersubjective in this case skilfully adjusts the locally relevant activity not as complaining but as expressing a concern. It is a turning point. 
After the claim to intersubjective understanding, the caller-taker moves to advising how the caller could do a more accurate estimate. The shift to advice-giving is um-prefaced. The placement of um after the claim to the intersubjective and before a turn constructional unit progressing a new action is consistent with Schegloff's (2010) observation that um can be a resource for exiting or reexiting a sequence. It is another indicator that suggests our target expression is functioning as a kind of transformative bridge to move from one activity to another. The movement is from a complaint in a sequential environment where affiliation and resolving a dispute is relevant to allaying a concern by giving advice.

In the next extract, as in the previous one, the target expression is in response to a troublestelling that is not an institutionally legitimate complaint for dispute resolution. Other important similarities shared by the two extracts are that the just prior action is formatted as a question and a stance aligning, affiliating response is clearly relevant. For the case presented below, an aspect of the reason for the call is that the utility company would like payment to come directly from the caller's state-paid dependent person's benefit (administered by Work and Income New Zealand or WINZ, the acronym used in the extract below). The extract begins as the caller is finishing explaining that he doesn't want the money taken directly from his benefit for tax purposes. The target expression occurs at line $13-$ I see this is frustrating you on alot of levels.

Extract 2 Dispute resolution service (NZE)

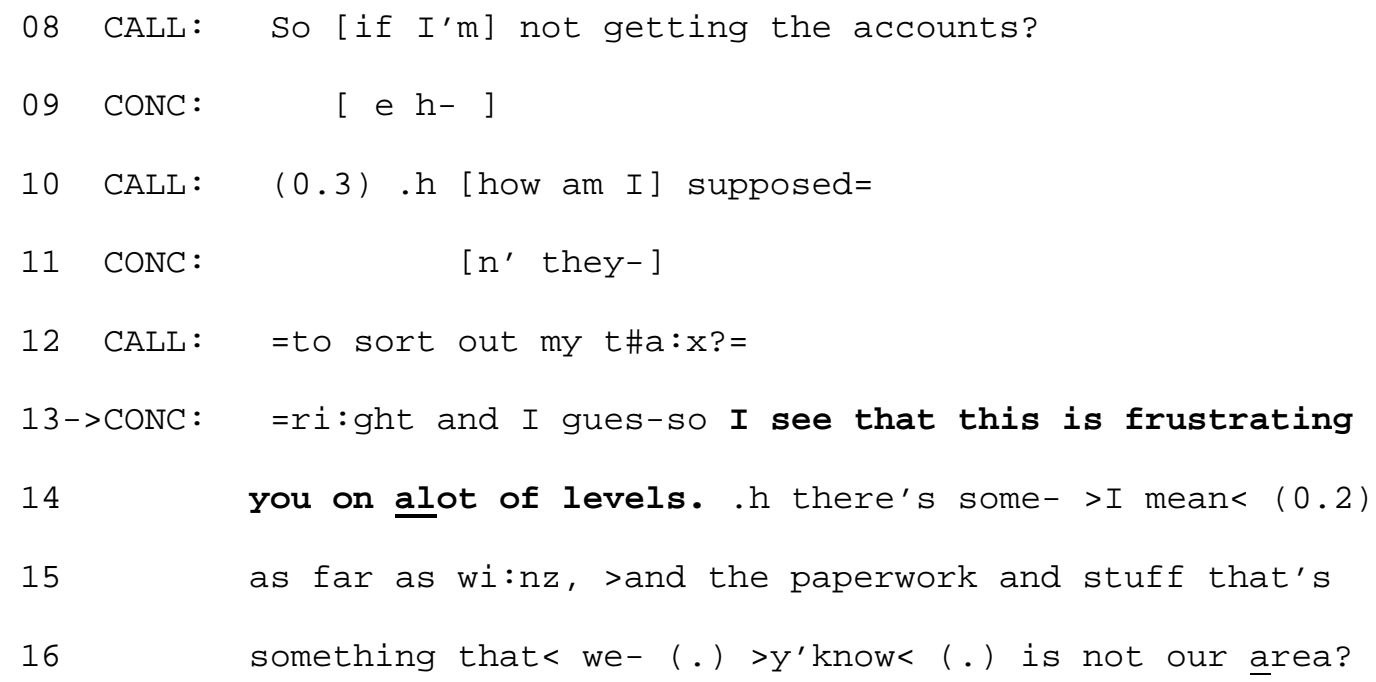



$(0.2)$.h but um, I wi: :ll (0.4) uhm record uhm all the fa- >All the information that you've given me toda:y< .H: did you wanna go into the complaints process today?

CALL: HHh: :

CONC: did you wanna start that?

CALL: $\quad$ YEAH>cos as far as I'm concerned< if nothing else it has be- definitely been harassment.

In Extract 2 the position of our target expression is in response to a turn that displays the caller's negative affective stance. The caller is objecting to a possible future when his electricity bills get paid directly out of his benefit entitlement and not from his bank account. The caller's turn has a compound construction where the first element is a negatively formulated conditional - if I'm not getting the accounts that is recognisable as complaining (Schegloff, 2007). In the above case the electricity accounts are needed for tax purposes as the second element of the compound construction shows - how am I supposed to sort my tax, so it is a rhetorical question. In this complaining environment the interrogative design of the turn acts as an assertion and conveys a stance that there is no adequate answer to the question (see Koshik, 2005). A relevant response from a properly aligned recipient would be some kind of agreement about the undesirability of direct-debits from benefit entitlements.

The call-taker actually responds to the caller's description of the undesirable future of direct payments with right, that displays no matching stance. After and I guess, a turn constructional unit that is abandoned, the turn is started again with so I see this is frustrating for you on a lot of levels. The word selection / see captures a sense of both understanding and appreciating. What is being 
understood is referred to as this - an indexical and vague reference to the cause of the caller's affective state. The cause of what has been formulated as the caller's frustration is also construed abstractly as having a lot of levels. Vagueness can function to avoid the accountability associated with detailed description (Potter, 1996). The vague formulation of the cause of the caller's stance neatly evades orienting to what is being aired as a legitimate complaint.

In contrast to the vague construal of the situational cause of the emotion, the affect is specifically named as frustration. The word selection conveys an understanding that the caller is being blocked from reaching desired outcomes. However, it displays no alignment with the caller's turn as a relevant complaint for dispute resolution nor does it endorse that stance. It is an ostensible display of affiliation when it is a relevant response. Furthermore, it acknowledges the prior turn without progressing it as a complaint. Rather the call-taker moves to a different activity - explaining what is within the institutional remit.

The issues of benefit-payment and paper-work are not relevant to the dispute resolution service - as far as winz and the paperwork and stuff...is not our area. Having informed the caller the call-taker cannot do anything about that aspect of the problem, the call-taker begins describing an institutionally relevant activity that she can progress. The move to the different activity is but um prefaced, as in the previous extract. The new action of the call-taker is an informing of what she will do next. She says she will record all the information - itself a particular formulation of what the caller has been doing that retrospectively neutralises the stance previously displayed. Then, she asks if the caller wants to proceed with the next step of dispute resolution, in which the electricity company contacts the caller. The caller aligns with the new activity, seen at the end of the above extract as an agreement to begin the complaints process.

In the third and final extract from the same setting, the caller's complaint is the electricity company is asking to do an additional reading because one was done incorrectly. Just prior to the extract below the caller explained her reluctance to give the meter reader a house key - a typical 
practice in cases where meters are inside, which is the case in the caller's house. That unwillingness stems from a past experience, disclosed just prior to the presented extract, of being accosted (caller's own term) by a meter reader. The extract below beings as the caller construes what happens when a meter reader has a house key - they just walk into your home. Her turn culminates in the question wouldn't that make you feel vulnerable. Our target expression is in the call-taker's responsive turn to that question.

Extract 3 Accosted by a meter reader

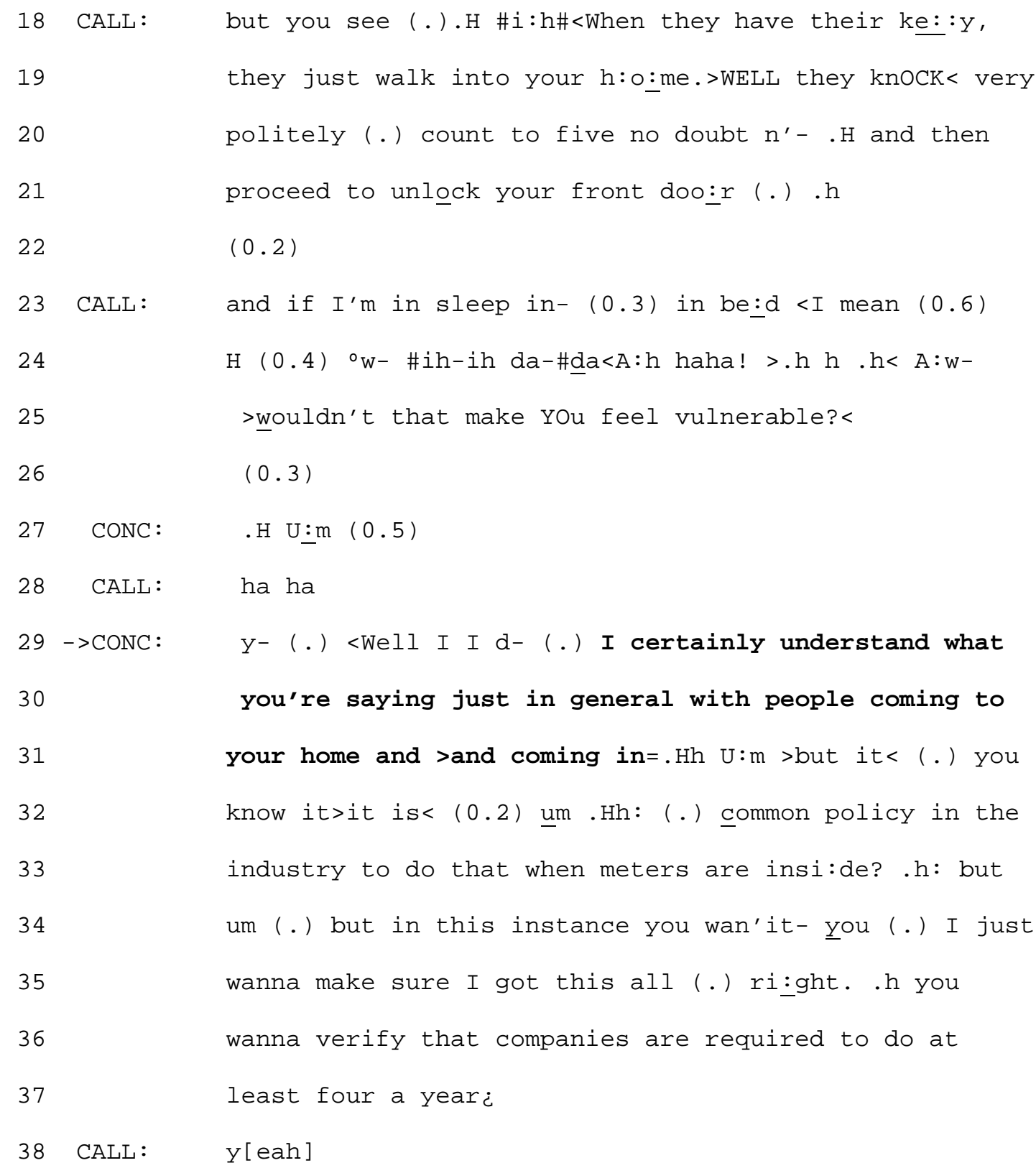


In the above extract our expression occurs in response to a story that is a hypothetical scenario that justifies not giving a meter reader a key. A preferred response to a story is one that endorses the teller's stance, which can be marked in various ways (see Sacks, 1974). In Extract 3 the caller's stance is displayed in the final unit of her turn wouldn't that make you feel vulnerable. That final unit has the format of what Koshik (2005) termed a reverse polarity question that functions to convey an assertion, in this case that it does make you feel vulnerable. A relevant and stance aligning response would be some kind of agreement or endorsement. However, agreement would condone withholding a key needed for meter access, which is not a legitimate act from the institutional perspective.

The call-taker's actual response to the caller's reverse polarity question is delayed, wellinitiated and contains perturbations - all established indicators of dispreferred responses (Schegloff, 2007). It also includes our target expression - I certainly understand what you're saying. Here we suggest the word saying is being used metonymically to refer to meaning so the claim is to understanding what is in the caller's mind. Directly following that expression the call-taker demonstrates her understanding by saying, just in general with people coming to your home and and coming in. The caller's story was a personal scenario where an individual meter readers use a key to let themselves into your locked home, uninvited. The situation is transformed by the call-taker's formulation to being a broad but rather vaguely specified principle. That is, in general, the call-taker is claiming and demonstrating agreement with the caller that there is a proper way for people to come into your home.

The target expression looks like affiliation because it claims the two parties are at one with each other about the matter at hand. However, it is a turning point - what follows in the turn of talk is actually contrastive - a but-prefaced explanation that actually justifies a counter position that is providing a key because it is common policy. Next in the turn is another shift in activity, again 
prefaced with but um. The call-taker requests confirmation that she understands the situation correctly. The caller aligns with the activity by confirming with yeah (line 38).

In all three cases examined so far aspects of what the caller is doing is ill-fitting or misaligned with the call-taker's task of progressing legitimate institutional business. The misalignment in Extract 1 is complaining about not getting monthly meter readings; in Extract 2 complaining about not getting sent accounts for tax records, and Extract 3 justifying withholding a house key when an electricity meter is inside. Furthermore, the caller's turns immediately prior to our target expressions all have an interrogative format - I mean is it gonna be another two months or another three months or before we know it we're gonna have over a threethousand dollar powerbill at Christmas time (Extract 1); If I'm not getting the accounts how am I supposed to sort my tax (Extracts 2), and Wouldn't that make you feel vulnerable (Extract 3). Each of these turns function more like assertions than questions and make agreement with the caller's viewpoint relevant. Agreeing would endorse the caller's stance on the matter, which is one way of showing of affiliation (Stivers, 2008).

By claiming an understanding of the other and formulating the nature of that understanding in psychological terms - in Extract 1 as a concern; in Extract 2 as frustration, and in Extract 3, as the speaker meaning something - the call-takers show the caller's view has sense while at the same time construing it as in the other's subjective realm (and by inference not their own view). The expression is pro forma affiliation in the way that it makes a show of being other-attentive but falls short of actual affiliation because it doesn't actually support the caller's stance. For all three cases, the pro forma expressions are part of a temporal move in the call-taker's turn away from what the caller was doing (making a complaint in order for it to be treated as a dispute to be resolved) to something else - advising (Extract 1), informing (Extract 2) and confirming (Extract 3). The new activity was uhm or but- prefaced in all cases, demonstrating the call-taker's orientation to the upcoming activity as contrastive rather than progressive.

All the target expressions examined so far accept the other has a view albeit not shared, so have a concessive feel to them. In a study of argumentation in interaction, Antaki \& Wetherell (1999) 
made a distinction between doing a concession and making a show of conceding. They found a show concession provided ostensible evidence that the speaker appreciates the other side's point of view while at the same time furthering an argument that does not. It gives a sense that the speaker is being balanced and fair-minded. The sequential organisation of above three cases: the caller's stance taking on a trouble; the call-taker's claim to the intersubjective, followed by the call-taker's move to a different activity also shares some characteristics of the three-part Concessive Structure identified by Couper-Kuhlen and Thompson (2000) where speaker A makes a point then speaker B acknowledges the validity of the point but goes on to make a contrasting one. The concessives examined by Couper-Kuhlen and Thompson were about objective matters whereas for our cases it is related to the caller's perspective. The caller displays a stance on a trouble, and the call-taker grants that stance by claiming understanding. It is not, however, strictly concessive because it does not acknowledge the validity of the caller's view. The concessive quality of the expression where there is no actual concession is part of its action of pro-forma affiliation.

\section{Claims to the Intersubjective in Non-Affiliation-Relevant Positions}

Affiliation is mostly conceptualized in conversation analytic work as made relevant by a prior action (Stivers 2008). It has been closely tied to preference, and thus to certain types of sequentially responsive positions such as in second pair parts of adjacency pair actions (Lindström \& Sorjonen 2013). As mentioned above, affiliation can be accomplished in a next turn by matching the evaluative stance of the prior speaker and when it is affective alignment, can be understood as the interactional accomplishment of an emotion such as empathy. It is often discussed by reference to social solidarity (see Lindström \& Sorjonen 2013:351-353). The analysis of the cases so far have shown our target expressions - claims to the intersubjective can and do occur in sequentially responsive positions - to questions that function like assertions and make agreement (rather than answers) and affiliation clearly relevant.

Responsivity, however, can also be understood as a more general phenomenon, whereby every act is selectively responsive to a complex array of contextual conditions that includes what others are 
doing in the environment (Linell, 2009). The cases that follow show the expression to be responsive in this broader sense. It is attentive to the other party in a way that is tied less to the just prior turn and more to a general pro-socialness. They are cases where the speaker has rights and responsibilities in a specific domain of action (i.e. as a host, as a set designer and as a teacher) which they move to advance in the face of some barrier posed by the recipient - a kind of misalignment not necessarily bound to the just prior turn of talk.

Before presenting cases to support our proposal that claims to the intersubjective are expressions that do pro forma affiliation in a more general sense, consider whether there is anything more pro-social or affiliative than the claim 'I understand (something about) you', which ostensibly formulates the other's actions as understandable, and by inference accepted or endorsed by the speaker. Together with the formulation of the other's perspective in psychological terms (their thoughts, emotions or desires) the expression construes a sense of a shared world where 'you and l' are of the same mind. We will now show the expression actually undermines this ostensibly affiliative potential and renders it as a pro forma device across a variety of speech situations. The following three examples serve to illustrate different misalignments that are handled by a claim to the intersubjective in the service of progressing a speaker's own interactional agenda.

Misalignment between guests and a host. Extract 4 is from an informal gathering of four elderly friends at A's home. At the beginning of the excerpt they are all sitting around a sofa table and talking about somebody who cannot dance any more. In the target lines (4-7) the host breaks this topic and asks everybody to move to the other larger table for refreshments. The claim to the intersubjective is deployed as a bridge into this new activity project.

Extract 4 Bridge night (in Swedish)

$1 \mathrm{C}: \quad$ han e aldri kvar=

he never stays for longer

2 A: $\quad=$ de e klart vettu de e svårt för honom ¿=

Sure, y'know, it's hard för him 


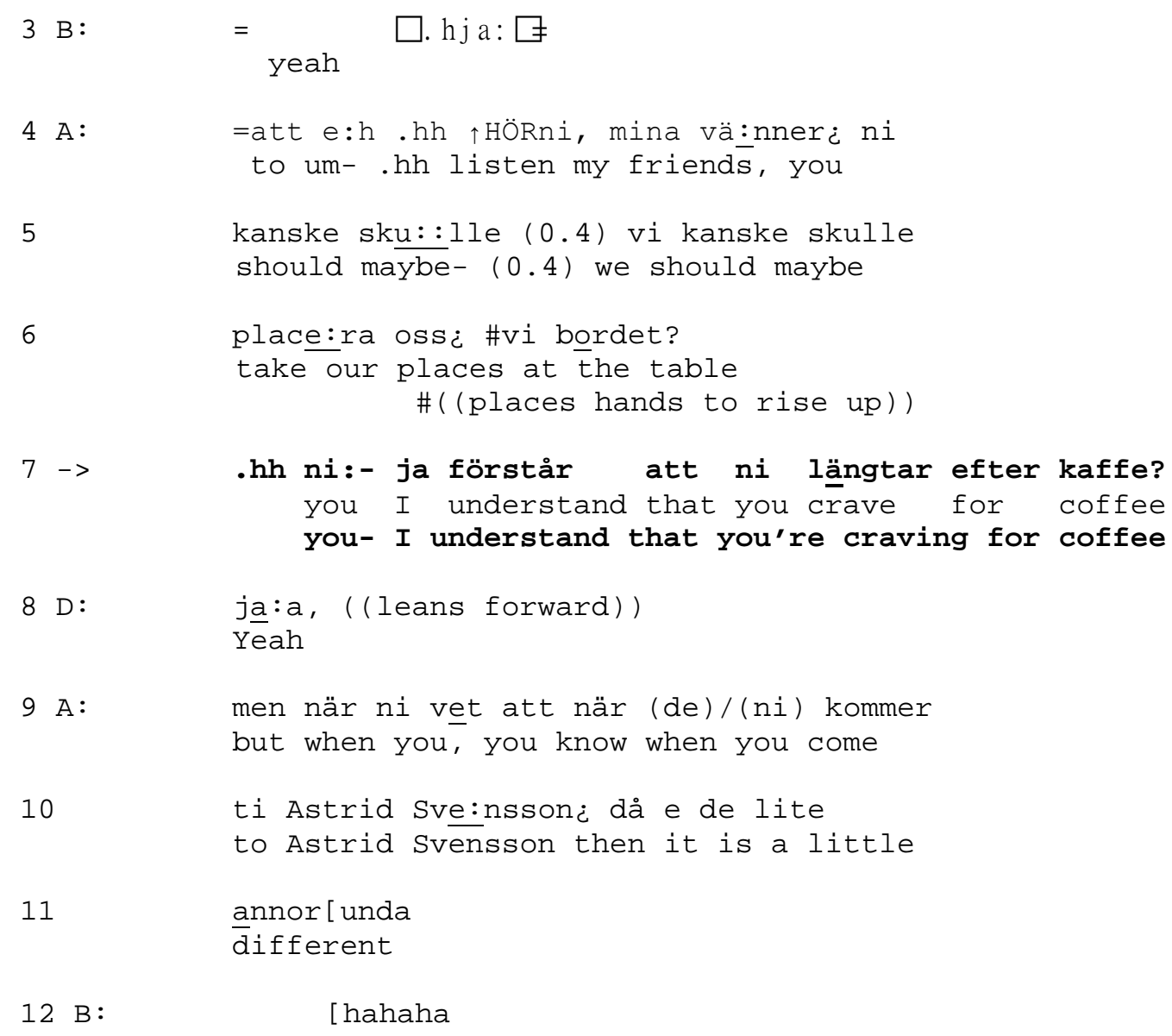

$12 \mathrm{~B}$ :

[hahaha

The excerpt starts with talk about somebody whose health is apparently failing. In line 2 the host A says 'it is hard for him'. She leans back on her chair and projects a continuation with the complementizer att 'that' (in line 4) but never realizes this projection. Instead, she breathes in, starts turning around towards the other larger table in the room and launches an invitation to sit there. By producing an assessment of the prior topic, leaning back, and abandoning the turn midway she has efficiently disengaged and is now accomplishing a major transition to a different activity, drinking coffee. One participant nods after her proposal but no one moves. Similar to our earlier examples, there is a moment of misalignment in the activities: the guests sitting (and chatting) and the host urging a move to the next activity.

Speaker A starts to rise from the chair (in line 6), while the others remain seated. There is a discrepancy between the static postures of the guests, their orientation to the prior spatial 
formation, and the host's moving to a new activity. Speaker A then produces a claim to the intersubjective 'I understand that you're craving for coffee' (in line 7). Thus she manages the lack of an aligning response by ascribing her motivation for the proposal to the recipients, the guests in the room. The formulation of the psychological state as 'craving' by others promotes the speaker's agenda as a host. In our target expression she construes a desire that her current proposal serves to satisfy. With the claim she implicitly makes the guests accountable for her offering the coffee, while performing the role of a proper hostess (which she then jokingly undermines in lines 10-12, building on the concessive potential of the claim to the intersubjective understanding). As a strategy to realign others to her new project, the pro-social and broadly affiliative claim is successful. The formulation of 'craving for coffee' is immediately confirmed by speaker D who leans forward to prepare for the move (line 8). The others follow soon (at the end of line 11).

Misalignment between work colleagues. Excerpt 5 comes from a face-to-face workplace meeting where the four participants have a joint goal of building a stage for an opera performance. At the focal point of our analysis two people are talking: the artist who drew the original sketches and the head of the workshop whose responsibilities include supervising the building of props, transporting them to the opera house and ensuring their proper function. It is thus in his interest to keep them cheap, small and robust. The artist, on the other hand, will be judged in terms of the aesthetic and inventive qualities of the design.

The participants have been moving around in different areas of the workshop and have now arrived at the welder. They have stopped in front of some metal structures that will become orientalstyle roofs on the stage. Prior to the focal turn, they have talked about the size of the stage and the problem that the welded roofs are quite small. This topic comes to a completion with nobody responding to the Welder's attempts to continue (lines 1-3). The artist brings up another aspect of the structures - some of them were originally planned to be cloth "plates" that would be dynamic and twirling (focus lines 4-6). In other words, they were not supposed to be made of metal and welded at all. The pile of the observable structures in front of them, however, enables the artist to 
raise this sensitive issue of 'centrifugal plates'. Her turn is responsive to the physical objects that constitute a materialized version of an interpretation of her original drawings. On tsent- 'cent-' the artist also points towards them (line 5 see Figure 1 ).

Extract 5 Theater workshop (in Estonian)

1 Welder: see pole $j(h) u k(h)$ õik. $h$ This is not all.

2

3 welder: siin juHere -

4 Artist:-> a ma saan aru et e se- seda nagu nobut I understand that thi- the/this:PRT like NO But I understand that thi- this like-

$5->\quad \begin{array}{ll}\text { nagu ned } \\ \text { like the/these }\end{array}$ you didn't consider/take into account

6 -> sa nagunii ei arvestanud onju. you anyway NEG consider:PPT right the centrifugal plates anyway right.

${ }^{\circ}$ et se ei ole vaet. ${ }^{\circ}$

so we can forget about that.

Figure 1. Artist pointing on tsent- 'cent-'

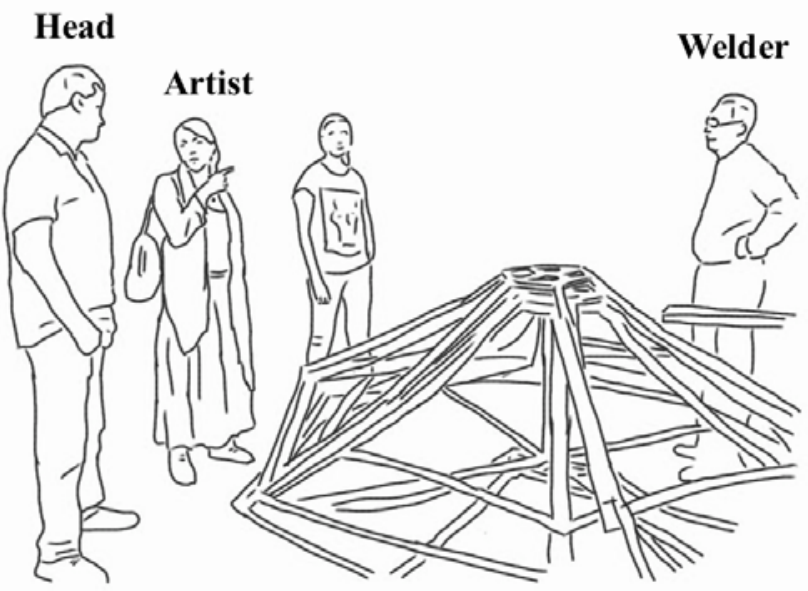

8 Head: eino mina kutujasin ette et Well I was imagining it

9 oopis teistmoodi on millegipärast. totally differently for some reason. $I^{\prime}$ ts where the spiral is right. 
11Artist: EI, spiraal on eraldi,
No, the spiral is separate,

The artist's 'I understand'-turn (line 4) is not a response to an immediately prior turn-at-talk, while the topic was touched upon half an hour earlier. She has also half-turned her upper body towards the workshop head, away from the welder who is talking (see Figure 1). That turn projects a continuation, and after some perturbation (moving from a noun phrase construction to a clausal one) she provides an account for the current appearance of the objects. She formulates it as her current recipient, the workshop head, 'didn't take into account' the idea of centrifugal plates - to take something into account is a psychological formulation because it refers to his decision-making. The expression is attentive to self-other relations because the complainable - a negative noticing - is formulated as an understandable matter, which maintains a pro-social stance. Such noticings tend to open up explanation slots in which addressees explain why they have behaved or not behaved in a certain way (MuntigI \& Horvath 2014). Indeed, in the following turn (lines 8-10) the head of the workshop gives an account for 'not taking into account the plates' which implies agreement with the artist's formulation of his inaction as well as responsibility for it. The talk progresses on the topic of 'centrifugal plates', enabling the artist to expand on her ideas. As in the prior cases, here the activity after the target expression is different from what it was before it. The expression in Extract 4 was a successful strategy for introducing a sensitive issue, a major misalignment that was a discrepancy between the plans and production of a structure, and accomplishing critique. It did so in an ostensibly pro-social and affiliative manner by claiming an 'understanding' of how the recipient had produced the problematic prop.

Misalignment between a teacher and a student. The next case, as in the previous one involves criticism. Extract 6 shows a dance teacher addressing a misalignment by a student in a class, albeit jokingly. She points out a mistake in his dance and goes on to interpret why it happened, namely because he wanted the lead role in the movie, perhaps as an obtuse reference to the videorecording being undertaken for research. The ascription of motivation behind his problematic 
performance simultaneously formulates an alternative activity of 'being in a movie' where it would have been reasonable to make such a dance step.

The excerpt starts by the teacher asking everybody to start dancing from a certain point in the choreography ('second swingout'). She then accompanies the dance by counting the beat numbers and calling out step names (lines 3-4). In line 5 she stops and in line 6 provides a negative noticing: a student named Eero has not performed the 'swingout' step. Our target expression follows in a smiling voice and interspersed with laughter (lines 7-10).

\section{Extract 6 Dance class (in Estonian)}

1 Tea: Nii. Läksime kõik veel teise swingouti So. We'll all go into the second swingout

2 ja pööre ring. (.) and turn circle. (.)

3 .h viis kuus seitse kaheksa. .h five six seven eight. swingout hopp ja samm samm hopp ja:-((sings)) Swingout hop and step step hop and[dance starts

6

See ei olnud swingOUT EE: : ro kallis. This was not a swingout Ee: :ro dear. dance stops ]

11

(. ) 
Five six seven eight.

Reacting to the incorrect step, the teacher construes it as an understandable matter, which somewhat mitigates the initial harsh judgement of the dance performance. She offers an explanation for the student's misalignment with the choreography and the rest of the class, implicitly formulating his performance as a deliberate solo for the sake of the movie, something the student really 'wanted'. Together with the initial noticing of the mistake 'this was not a swingout', the joke serves to advance the task of teaching the students to do the right steps of the dance, and the claim to the intersubjective understanding emerges as a concessive.

This section has shown that the use of our target expressions is not confined to one institutional setting nor tied to sequential positions where affiliation is relevant. Rather, they are deployed in a range of settings at moments of smaller or larger misalignments, with more or less at stake for speakers as they advance activities in their realm of responsibilities. Likewise, the meaning of 'understanding' emerges as slightly different in each of these settings, depending on what the speaker is reacting to and what is specified as the content of the understanding.

\section{Concluding Comments}

This study examined expressions with the general form I 'understand' + YOU + PSYCHOLOGICAL FORMULATION. Using conversation analysis we asked where in talk these rather extreme and relatively rare expressions are used and to what interactional ends. We found they occur when there is misalignment of some kind between the parties and the speaker progresses an activity related to their own interactional project or concerns.

In the cases from the telephone-mediated dispute resolution service the expression all occurred in sequential positions where affiliation - in the established conversation analytic sense of stance alignment - was clearly relevant but where it was professionally impossible for the call-taker to provide it. In this specific institutional setting that required the 'neutral' handling complaints the 
use of the expression in affiliation relevant position was almost routinized and arguably recognisable in its tokenistic affiliation.

In settings where the activities were not clearly shaped by institutional concerns the sequential position deployment of the expression was less fixed. Nevertheless, its other-attentive, concessive, misalignment-managing character held, supporting our proposal that it is a general form for doing pro forma affiliation. Across all settings the speaker had specific albeit different rights and responsibilities for making things happen related to their role or category membership (that is, as a conciliator, host, set designer and teacher). Participants' orientations to authority in specific domains of action are an aspect of deontic reasoning. In conversation analytic work deontics has been discused with respect to directives (Stevanovic \& Svennevig, 2015). For example, by showing the way doctors and patients defer to each other's rights and responsibilities around proposed courses of treatments (Lindström \& Weatherall, 2015). It seems possible that our target expression invokes deontic authority because it occurs at a pivotal moment in terms of action, where a speaker is bridging a move to recruit another party to a new activity associated with the speaker's categorymembership bound concerns. Support for this possibility requires further research but our findings support the idea that deontic authority may be invoked as a resource for promotting one course of action over another.

Using an explicit claim to intersubjective understanding when there is misalignment gives the impression of other-consideration and is consistent with other structures that have been discussed in terms of a general orientation to pro-sociality. One example is dispreferred second pair parts, where there can be several components that support social cohesion including palliatives and accounts that regularly involve 'no fault' explanations such as inability (Heritage, 1988; Schegloff, 2007). Token agreement strategies are another example (Pomerantz, 1984; Niemi, 2014; Szczepek Reed, 2015). We suggest that our expression is also a conversational practice that shows an orientation to pro-sociality. Our target expression contains a formulation of another party's psychological state. Studies of speakers' formulations of prior talk in institutional settings have found they are used to support 
relevant action. For example mediators formulate disputant's views to moderate emotive descriptions (Garcia, 1991) and psychotherapists can use formulations of client's talk to advance therapeutic activities (Antaki, 2008). The psychological formulations in our target expressions not only demonstrated claimed understanding but also could be used to support the progression of a next action - for example, in Extract 1 the formulation of a prior turn as displaying concern supported the move to advice for how to address the concern. In Extract 4 the formulation of the guests as craving for coffee supported the host's move to the dining table for refreshments.

Studies in discursive psychology and conversation analysis have examined various expressions drawing on the cognitive thesaurus. Our research extends previous work because its empirical focus examined a more complex structure that draws twice on the cognitive thesaurus. Furthermore, it adds to a growing body of evidence that certain grammatical-conversational structures have a strategic origin in social interaction.

\section{References}

Antaki, C. (2012). Affiliative and disaffiliative candidate understandings. Discourse Studies, 14(5), 531-547, DOI: 10.1177/1461445612454074

Antaki, C. (2008). Formulations in psychotherapy. In A. Peräkylä, C. Antaki, S. Vehviläinen and I Leudar (Eds.), Conversation analysis and Psychotherapy, (pp. 26-42). Cambridge: Cambridge University Press.

Antaki, C., \& Wetherell, M. (1999). Show Concessions. Discourse Studies, 1, 7-27.

Asmuss, .B. (2011). Proposing shared knowledge as a means of pursuing an agreement. In T. Stivers, L. Mondada \& J. Steensig (Eds.), The Morality of Knowledge in Conversation, (pp. 207-234). Cambridge: Cambridge University Press.

Beach, W.A. (1993). Transitional regularities for 'casual' "Okay" usages. Journal of Pragmatics, 19, $325-352$. 
Bolden, G.B. \& Robinson, J.D. (2011). Soliciting accounts with Why-interrogatives in conversation. Journal of Communication, 61, 94-119.

Coulter, J. 1979. The social construction of mind: Studies in ethnomethodology and linguistic philosophy. Totowa, NJ: Rowman and Littlefield.

Couper-Kuhlen, E. (2012). Exploring affiliation in the reception of conversation complaint stories. In A. Peräkylä and M-L. Sorjonen. Emotion in interaction, (pp. 113-146). Oxford: Oxford University Press.

Couper-Kuhlen, E. \& Thompson, S.A. ( 2000). Concessive patterns in conversation. In E. CouperKuhlen \& B. Kortmann (Eds.), Cause-Condition-Concession-Contrast: Cognitive and Discourse Perspectives, (pp. 381-410). Berlin, New York: Mouton de Gruyter.

Drew, P. (2003). Comparative analysis of talk-in-interaction in different institutional settings: A sketch. In P. J. Glenn, C. D. LeBaron, \& J. Mandelbaum (Eds.), Studies in language and social interaction: In honor of Robert Hopper (pp. 293-308). Mahwah, NJ: Erlbaum.

Edwards, D. (2005). Moaning, whinging and laughing: the subjective side of complaints. Discourse Studies, 7, 5-29.

Edwards, D. (1997). Discourse and cognition. London: Sage.

Edwards, D. (1995). Sacks on psychology. Theory \& Psychology, 5 (4), 579-596. DOI: $10.1177 / 0959354395054006$

Garcia, A. (1991). Dispute resolution without disputing: How the interactional organisation of mediation hearings minimizes argument. American Sociological Review, 56, 818-835.

Gardner, R. (2007). The Right connections: Acknowledging epistemic progression in talk. Language in Society, 36, 319-341.

Heritage, J. (1988). Explanations as accounts. In C. Antaki (Ed.), Analysing everyday explanation: A case book of methods (pp. 127-144). London: Sage.

Jefferson, G. (1988). On the sequential organization of troubles-talk in ordinary conversation. Social Problems, 45, 418-441. 
Jefferson, G. \& Lee, J. (1981). The rejection of advice: Managing the problematic convergence of a 'troubles-telling' and a 'service encounter'. Journal of Pragmatics, 5, 399-422.

Kärkkäinen, E. (2007). The role of I guess in conversational stance taking. In R. Engelbretson (Ed.), Stance taking in discourse: Subjectivity, evaluation, interaction, (pp. 183-219). Amsterdam: John Benjamins.

Kärkkäinen, E. (2003). Epistemic stance in English conversation: A description of its interactional functions, with a focus on "I think." Amsterdam: John Benjamins.

Keevallik, L. (2006) From discourse pattern to epistemic marker: Estonian (ei) tea 'don't know'. Nordic Journal of Linguistics, 29(2), 173-200.

Koshik, I. (2005). Beyond rhetorical questions in everyday interaction. Amsterdam: John Benjamins. Lindström, A. \& Sorjonen, M-L. (2013). Affiliation in conversation. In J. Sidnell \& T. Stivers (Eds.), The Handbook of Conversation Analysis (pp. 350-369). Malden, MA: Wiley-Blackwell.

Lindström, A. \& Weatherall, A. (2015). Medical and Life World Contingencies in Treatment Proposals. Journal of Pragmatics, 78, 39-53. DOI:10.1016/j.pragma.2015.01.005

Lindström, J. \& Wide, C. (2005). Tracing the origins of a set of discourse particles: Swedish expressions of the type 'you know'. Journal of Historical Pragmatics, 6(2), 211-236.

Lindwall, O., \& Lymer, G. (2011). Uses of "understand" in science education. Journal of Pragmatics, 43(2), 452-474. DOI: 10.1016/j.pragma.2010.08.021

Linell, P. (2009). Rethinking language, mind, and world dialogically. Charlotte, NC: Information Age Publishing.

Maynard, D.W. (2013). Defensive mechanisms: I-mean-prefaced utterances in complaint and other conversational sequences. In M. Hayashi, G. Raymond \& J. Sidnell (Eds.). Conversational repair and human understanding, (pp. 128-233). Cambridge: Cambridge University Press. Mondada, L. (2011). Understanding as an embodied, situated and sequential achievement in interaction. Journal of Pragmatics, 43, 542-552. DOI: 10.1016/j.pragma.2010.08.019 Muntigl, P. \& Horvath, A.O. (2014). "I can see some sadness in your eyes": When experiential 
therapists notice a client's affectual display. Research on Language and Social Interaction, 47(2), 89-108. DOI:10.1080/08351813.2014.900212

Niemi, J. (2014). Two 'yeah but' formats in Finnish. The prior action engaging nii mut and the disengaging joo mut utterances. Journal of Pragmatics, 60, 54-74.

Pomerantz, A (1984) Agreeing and disagreeing with assessments: some features of preferred/dispreferred turn shapes, In J.M Atkinson \& J. Heritage (Eds.), Structures of social interaction: studies in conversation analysis, (pp. 57-101). Cambridge: Cambridge University Press.

Potter, J. (2006). Cognition and conversation. Discourse Studies, 8 (1), 131-140. DOI: $10.1177 / 1461445606059562$

Potter, J. (1996). Representing reality. Discourse, rhetoric and social construction. London: Sage.

Sacks, H. (1992). Lectures on conversation (Vols. I and II). G. Jefferson (Ed.). Oxford: Basil Blackwell.

Sacks, H. (1974). An analysis of the course of a joke's telling in conversation. In R. Bauman and J. Sherzer (Eds.), Explorations in the ethnography of speaking, (pp. 337-354). Cambridge: Cambridge University Press.

Schegloff, E.A. (2010). Some other "Uh(m)"'s. Discourse Processes, 47, 130-174.

Schegloff, E. A. (2007). Sequence organization in interaction. Cambridge: Cambridge University Press. Schegloff, E.M. (2005). On Complainability. Social Problems, 52, 449-476.

Schegloff, E.A. (1996). Confirming allusion: Toward an empirical account of action. American Journal of Sociology, 102, 161-216. Article Stable URL: http://www.jstor.org/stable/2782190 Sczcepek Reed, Beatrice 2015. Managing the boundary between 'yes' and 'but': Two ways of disaffiliating with German 'ja aber' and 'jaber'. Research on Language and Social Interaction $48(1), 32-57$.

Schiffrin, D. (1987). Discourse Markers. Cambridge: Cambridge University Press.

Smith, M. (2013). 'I thought' initiated turns: Addressing discrepancies in first-hand and second-hand knowledge. Journal of Pragmatics, 57, 318-330. DOI: 10.1016/j.pragma.2013.09.006 
Stevanovic, M. \& Svennevig, J. (2015). Introduction: Epistemics and deontics in conversational directives. Journal of Pragmatics, 78, 1-6. DOI:

10.1016/j.pragma.2015.01.008

Stivers, T. (2008). Stance, alignment and affiliation during story telling: When nodding is a token of preliminary affiliation. Research on Language in Social Interaction 41, 29-55.

Weatherall, A. (2015). "But whose side are you on?" Doing being independent in telephonemediated dispute resolution. In F. Chevalier J. Moore (Eds.), Producing and Managing Restricted Activities. Avoidance and withholding in institutional interaction (151-179). Amsterdam: John Benjamins.

Weatherall, A. (2011). I don't know as a pre-positioned hedge. Research on Language and Social Interaction, 44 (4), 317-337. DOI: 10.1080/08351813.2011.619310 